\title{
AVALIAÇÃO QUÍMICA DA FOLHA DE CENOURA VISANDO AO SEU APROVEITAMENTO NA ALIMENTAÇÃO HUMANA ${ }^{1}$
}

\author{
GLÁUCIA IMACULADA SOARES PEREIRA ${ }^{2}$ \\ ROSEMARY GUALBERTO F. ALVARENGA PEREIRA ${ }^{3}$ \\ MARIA DE FÁTIMA PÍCCOLO BARCELOS ${ }^{3}$ \\ AUGUSTO RAMALHO DE MORAIS ${ }^{4}$
}

\begin{abstract}
RESUMO - Visando a diminuir o desperdício de alimentos, com a utilização de partes vegetativas de hortaliças tradicionais, realizou-se o presente trabalho, por meio do qual objetivou-se caracterizar quimicamente a folha de cenoura. As folhas de cenoura foram submetidas à secagem em estufa a $60{ }^{\circ} \mathrm{C}$ por 72 horas. Em seguida, o material seco foi triturado e homogeneizado para posterior análise. Foram determinados a composição centesimal, vitamina $C$ total e $\beta$-caroteno, fibras
\end{abstract}

\begin{abstract}
dietéticas (FDN e FDA), pH, acidez total titulável, teores de minerais ( $\mathrm{Na}, \mathrm{P}, \mathrm{K}, \mathrm{Ca}, \mathrm{Mg}, \mathrm{Mn}, \mathrm{Zn}$ e Fe) e nitrato. Os resultados foram baseados em matéria-seca, e concluiu-se que as folhas de cenoura apresentaram teores significativos de vitamina $C$ total e $\beta$ caroteno, podendo ser considerada como fonte de fibras dietéticas e minerais, destacando-se o $\mathrm{Ca}$ e o Fe. Quanto ao teor de nitrato encontrado, este apresenta-se com teor aceitável.
\end{abstract}

TERMOS PARA INDEXAÇÃO: Folha de cenoura, alimentação humana, composição química.

\section{CARROT LEAF CHEMICAL EVALUATION AIMING ITS USE IN HUMAN FEEDING}

\begin{abstract}
This work was carried out aiming to minimize food waste through using for food the vegetative parts of traditional vegetables. This study sought to chemically characterizing the carrot leaf. Carrot leaves underwent oven-drying at $60^{\circ} \mathrm{C}$ for $72 \mathrm{~h}$. Next, the dry material was ground and homogenized for posterior analysis. It was determined the centesimal
\end{abstract}

composition, total vitamin $\mathrm{C}$ and $\beta$-carotene, diet fibers (FDN and FDA), pH, total acidity, mineral contents (Na, $\mathrm{P}, \mathrm{K}, \mathrm{Ca}, \mathrm{Mg}, \mathrm{Mn}, \mathrm{Zn}$, and $\mathrm{Fe}$ ), and nitrate. Carrot leaves feature significant amounts of total vitamin $\mathrm{C}$ as well as $\beta$ carotene. Additionally, they should be considered a source of dietary fibers and minerals, especially $\mathrm{Ca}$ and $\mathrm{Fe}$. Nitrate contents were found in acceptable levels.

INDEX TERMS: Carrot leaf, human feeding, chemical composition.

\section{INTRODUÇÃO}

Nas últimas décadas, a população mundial vem aumentando de maneira acentuada, exigindo um melhor aproveitamento dos recursos alimentícios disponíveis, para que essa população possa manter um nível de alimentação com alto valor nutritivo.

As deficiências minero-vitamínicas, principalmente as de vitamina A, riboflavina, folatos e ferro, afetam os grupos mais vulneráveis da população, acarretando pro- blemas de saúde pública, com graves conseqüências para o desenvolvimento do País (Flores et al., 1998).

Os resíduos de frutas e hortaliças são, geralmente, desprezados pela indústria e poderiam ser utilizados como fontes alternativas de nutrientes, com o objetivo de aumentar o valor nutritivo da dieta de populações carentes, bem como solucionar deficiências dietéticas do excesso alimentar. Além dessa contribuição, sabe-se que várias folhas, geralmente não incluídas na dieta habitual, são consideradas excelentes fontes de fibras

\footnotetext{
1. Parte da dissertação de mestrado do primeiro autor, apresentada à UNIVERSIDADE FEDERAL DE LAVRAS/ UFLA - Caixa Postal 37 - 37200-000 - Lavras, MG.

2. Nutricionista, M.Sc. em Ciência dos Alimentos - DCA/UFLA. glauciap@ufla.br

3. Professor Adjunto, Departamento de Ciência dos Alimentos - DCA/UFLA.

4. Professor Adjunto, Departamento de Ciências Exatas - DEX/UFLA.
} 
dietéticas utilizadas na prevenção de doenças cardiovasculares e gastrointestinais (Espíndola, 1987).

A utilização de alimentos alternativos para o combate à fome na população de baixa renda é assunto que tem recebido atenção no Brasil nos últimos anos, especialmente em razão do drama crescente da população carente. Diante do quadro social e econômico da população brasileira, o estudo da utilização integral de hortaliças no uso doméstico, bem como sua incorporação na elaboração de produtos industrializados, pode contribuir substancialmente para aumentar a disponibilidade de nutrientes, sendo uma fonte de baixo custo de proteínas, fibras, vitaminas e minerais.

Assim, em vista dos problemas de desnutrição das populações menos favorecidas e do desperdício das folhas de algumas hortaliças, caracterizou-se quimicamente a folha de cenoura, geralmente não consumida, com o objetivo de avaliar a composição centesimal, teores de minerais, vitamina $\mathrm{C}, \beta$-caroteno e nitrato, visando a determinar o seu potencial de utilização na alimentação humana.

\section{MATERIAL E METÓDOS}

Matéria prima: Foram utilizadas no presente trabalho as folhas de cenoura (Daucus carota L. cv. Brasília), cultivada em uma propriedade agrícola do município de Lavras-MG. A cultura foi conduzida de acordo com o recomendado para a espécie. A colheita do material foi efetuada no momento adequado à utilização das raízes para o consumo.

Preparo da folha de cenoura: As cenouras, com as respectivas folhas, foram colhidas no início da manhã. As folhas foram separadas e lavadas em água corrente e, em seguida, lavadas novamente em água destilada. Após retirar o excesso de água, o material foi levado para estufa a $60^{\circ} \mathrm{C}$ por 72 horas. O material seco foi triturado em moinhos de facas, homogeneizado e depois armazenado em frascos de vidro envolvidos com papel-alumínio, sendo, assim, protegidos da luz direta e mantidos em temperatura ambiente.

Determinações Químicas: A determinação do teor de umidade, de cinzas e de extrato etéreo foi realizada de acordo com os procedimentos descritos pela AOAC (1990). O teor de proteína $(\mathrm{N} \times 6,25)$, segundo o método de Micro-Kjedahl, conforme AOAC (1990). A fibra bruta foi extraída por hidrólise ácida segundo metodologia de Kamer \& Ginkel (1952). As determinações de FDA e FDN foram feitas pelo método proposto por Soest \& Wine (1968), citados por Silva (1981). A vitamina $\mathrm{C}$ total foi determinada pelo método calorimétrico de Roe \& Kuether, citados por Strohecker \& Henning (1967). O $\beta$-caroteno foi obtido de acordo com as Normas Analíticas do Instituto Adolfo Lutz (1985). O nitrato foi determinado pelo método de Cataldo et al. (1975). A determinação dos minerais: $\mathrm{Na}, \mathrm{P}, \mathrm{K}, \mathrm{Ca}$, $\mathrm{Mg}, \mathrm{Mn}, \mathrm{Zn}$ e Fe foram determinados por Espectrofotometria de Absorção Atômica com chama de acetileno, segundo metodologia estabelecida por Fiske \& Subbarow (1925) e Sarruge \& Haag (1974). Todas essas determinações foram realizadas com cinco repetições.

\section{RESULTADOS E DISCUSSÃO}

\section{Composição química}

$\mathrm{Na}$ Tabela 1 encontram-se os valores percentuais (b.s.) da composição centesimal das folhas de cenoura. O valor de umidade da folha de cenoura foi de $7,20 \%$ b.s. e está muito próximo ao valor encontrado por Sartorelli (1998) em folha de cenoura, que foi de 7,33\% b.s.

Quanto ao teor de proteína, Espíndola (1987) e Sartorelli (1998) encontraram, na folha de cenoura, valores de $26,5 \%$ e $19,82 \%$, respectivamente.

$\mathrm{O}$ teor de fibra bruta encontrado na folha de cenoura, conforme a Tabela 1, foi de 12,0\% b.s. Sartorelli (1998) encontrou, para folhas secas de cenoura e beterraba, teores de $18,26 \%$ e $10,66 \%$, respectivamente. Maffia (1991) cita valores de fibra bruta (\% no material seco) em alguns alimentos considerados fontes de fibra: milho integral $(3,0 \%)$; cenoura $(6,0 \%)$; repolho $(8,0 \%)$; farelo de trigo integral $(11,0 \%)$; aveia integral e farelo de arroz $(13,0 \%)$. Comparando esses valores com o encontrado nas folhas de cenoura, pode-se, então, considerá-las uma boa fonte de fibras.

O teor médio de carboidratos (extrato não nitrogenado) encontrado nas folhas de cenoura analisadas foi de $52,65 \%$ b.s., o que corresponde a $10,5 \%$ na matéria integral, podendo-se, assim, classificar as folhas de cenoura como um vegetal do tipo B por possuírem cerca de $10 \%$ de glicídios totais, segundo a classificação proposta por Ornellas (1979).

$\mathrm{O}$ valor calórico encontrado nas folhas de cenoura foi de 293,56 kcal.

Na Tabela 2 são apresentados os teores médios de fibra detergente neutro (FDN), fibra detergente ácido (FDA), pH e acidez total titulável (ATT) encontrados na folha de cenoura, bem como seus respectivos erros-padrão.

Considerando os teores de FDN e FDA, observase, pela Tabela 2, que a folha de cenoura apresentou teor representativo de fibras dietéticas, com base em Spiller \& Shipley, citados por Maffia (1991). Os autores apresentaram o conteúdo aproximado de fibra detergente neutro (FDN) em alguns alimentos, como: milho integral $(13 \%)$, aveia integral (31\%), farelo integral (45\%) e farelo de arroz (24\%). Quando se comparam esses valores de FDN na matéria seca com o obtido na folha de cenoura, que foi de $23,0 \%$, nota-se que este é próximo ao encontrado no farelo de arroz. 
TABELA 1 - Valores médios e respectivos erros-padrão da composição centesimal das folhas de cenoura*.

\begin{tabular}{lcccccc}
\hline & $\begin{array}{c}\text { Umidade } \\
(\boldsymbol{\%})\end{array}$ & $\begin{array}{c}\text { Cinzas } \\
(\boldsymbol{\%})\end{array}$ & $\begin{array}{c}\text { Fibra Bruta } \\
(\boldsymbol{\%})\end{array}$ & $\begin{array}{c}\text { Proteína } \\
(\boldsymbol{\%})\end{array}$ & $\begin{array}{c}\text { Extrato Etéreo } \\
(\boldsymbol{\%})\end{array}$ & $\begin{array}{c}\text { Carboidratos } \\
(\boldsymbol{\%})\end{array}$ \\
\hline Folha de cenoura & $7,20(0,07)$ & $10,5(0,33)$ & $12,0(0,26)$ & $15,12(0,52)$ & $2,50(0,12)$ & $52,65(0,67)$ \\
\hline
\end{tabular}

*Valores expressos em base seca.

TABELA 2 - Valores médios e respectivos erros-padrão para fibra detergente neutro (FDN), fibra detergente ácido (FDA), pH e acidez total titulável (ATT) da folha de cenoura.

\begin{tabular}{|c|c|c|c|c|}
\hline & $\begin{array}{l}\text { FDN } \\
(\%)\end{array}$ & $\begin{array}{c}\text { FDA } \\
(\%) \\
\end{array}$ & PH & 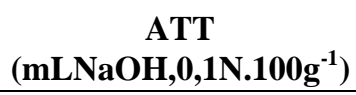 \\
\hline Folha de cenoura & $23,0(0,63)$ & $20,0(0,28)$ & $5,76(0,004)$ & $0,74(0,0024)$ \\
\hline
\end{tabular}

Pourchet-Campos (1990) obteve valores de FDN e FDA para algumas hortaliças e frutas, como alface $(13,16 \%$ e $9,19 \%)$, couve-flor cozida $(13,77 \%$ e $8,96 \%)$, abobrinha cozida $(35,23 \%$ e $25,88 \%)$, chuchu cozido $(25,64 \%$ e $19,74 \%)$ e mamão $(10,63 \%$ e $8,81 \%)$. Portanto, a folha de cenoura destaca-se como fonte de fibras (FDN e FDA).

\section{Vitamina $C$ e $\beta$-caroteno}

Os resultados encontrados para vitamina $\mathrm{C}$ e $\beta$ caroteno (mg/100 g b.s.) na folha de cenoura são apresentados na Tabela 3.

TABELA 3 - Valores médios e respectivos erros-padrão para vitamina $\mathrm{C}$ total e $\beta$-caroteno na folha de cenoura*.

\begin{tabular}{lcc}
\hline & $\begin{array}{c}\text { Vitamina C } \\
(\mathbf{m g} / \mathbf{1 0 0} \mathbf{g})\end{array}$ & $\begin{array}{c}\boldsymbol{\beta} \text {-Caroteno } \\
(\mathbf{m g} / \mathbf{1 0 0} \mathbf{g})\end{array}$ \\
\hline Folha de cenoura & $203,70(3,80)$ & $8,70(0,32)$ \\
\hline
\end{tabular}

\section{* Resultados expressos na base seca.}

Os valores de vitamina $\mathrm{C}$ e $\beta$-caroteno encontrados por Sartorelli (1998) no material seco de folha de beterraba foram de $72,42 \mathrm{mg} / 100 \mathrm{~g}$ e $24,78 \mathrm{mg} / 100 \mathrm{~g}$, e na folha de cenoura, foram de $34,93 \mathrm{mg} / 100 \mathrm{~g}$ e $5,71 \mathrm{mg} / 100 \mathrm{~g}$, respectivamente. Franco (2000) apresenta valores de vitamina $C$ de 50 $\mathrm{mg} / 100 \mathrm{~g}$ e de $\beta$-caroteno de $3,15 \mathrm{mg} / 100 \mathrm{~g}$, em folhas de beterraba.

As diferenças entre os teores de vitamina $\mathrm{C}$ do presente trabalho (Tabela 3) e os da literatura podem ser atribuídas às diferenças varietais, às condições climáticas de cultivo e à época de colheita. Os teores de vitamina C são maiores em plantas que receberam maior insolação (Hulme, 1970), e o conteúdo de ácido ascórbico de frutas e hortaliças varia com as condições sob as quais eles cresceram e o grau de maturação quando realizada a colheita. A vitamina $\mathrm{C}$ possui múltiplas funções no organismo, sendo necessária para a produção e manutenção do colágeno nos tecidos fibrosos, promovendo a cicatrização dos ferimentos, fraturas e contusões (Mahan \& Arlin, 1994)

O teor de $\beta$-caroteno encontrado na folha de cenoura analisada, conforme Tabela 5 , foi de 8,70 $\mathrm{mg} / 100 \mathrm{~g}$, sendo, portanto, maior que o teor encontrado na porção comestível convencional, a raiz, que se encontra na ordem de $6,6 \mathrm{mg} / 100 \mathrm{~g}$ (Franco, 2000). A vitamina A exerce função no crescimento, na reprodução e na prevenção da xeroftalmia (Dutra de Oliveira \& Marchini, 1998).

\section{Nitrato}

Os resultados das análises de nitrato na folha de cenoura encontram-se na Tabela 4.

TABELA 4 - Valor médio e respectivo erro-padrão para o nitrato na folha de cenoura*.

\begin{tabular}{cc}
\hline & $\begin{array}{c}\text { Nitrato }(\mathbf{m g} / \mathbf{1 0 0} \mathbf{g}) \\
\text { da folha de cenoura }\end{array}$ \\
\hline Folha de cenoura & $649,50(0,01)$ \\
\hline Resultados expressos na base seca. \\
Conforme pode ser visto na Tabela 4, o valor \\
de nitrato de $649,50 \mathrm{mg} / 100 \mathrm{~g}$ para a folha de cenoura
\end{tabular}


encontra-se elevado, quando comparado com os valores de Araújo (1995), que apresenta o teor de nitrato em alguns alimentos, como beterraba $(2,40 \mathrm{mg} / 100 \mathrm{~g})$, espinafre $(220 \mathrm{mg} / 100 \mathrm{~g})$ alface $(110 \mathrm{mg} / 100 \mathrm{~g})$ e cenoura $(20$ $\mathrm{mg} / 100 \mathrm{~g}$ ). Os teores de nitrato dependem e variam com a quantidade de nitrato disponível no solo e água.

Segundo a Organização Mundial da Saúde, citado por Toyohara (1989), a ingestão diária aceitável para nitrato para o homem é de $5 \mathrm{mg} / \mathrm{kg}$ de peso corporal. Portanto, um adulto com $70 \mathrm{~kg}$ não deve ingerir mais de $350 \mathrm{mg} /$ dia de nitrato, o que torna possível o consumo de folha de cenoura em uma quantidade de aproximadamente $50 \mathrm{~g} / \mathrm{dia}$.

\section{Minerais}

Os teores médios dos minerais encontrados na folha de cenoura foram expressos na matéria seca e encontram-se na Tabela 5.

$\mathrm{O}$ teor de $\mathrm{Na}$ encontrado nas folhas de cenoura (material seco) foi de $32,80 \mathrm{mg} / 100 \mathrm{~g}$. Esse resultado encontra-se próximo aos teores de algumas hortaliças de consumo habitual, como agrião (33,2 $\mathrm{mg} / 100 \mathrm{~g})$, alface $(34 \mathrm{mg} / 100 \mathrm{~g})$, couve-flor (34 $\mathrm{mg} / 100 \mathrm{~g})$ e vagem $(34,1 \mathrm{mg} / 100 \mathrm{~g})$, segundo Franco (2000). O Na é importante na transmissão dos impulsos nervosos, mantém a pressão sanguínea, além de atuar nos sistemas de transporte de aminoácidos, glicose e diversos íons através das membranas (Brody, 1994).

Conforme demonstrado na Tabela 5, o resultado para o $\mathrm{P}$ encontra-se próximo ao de alimentos considerados fontes alimentares de $\mathrm{P}$, como queijo $(430 \mathrm{mg} / 100 \mathrm{~g})$, gema de ovo $(500 \mathrm{mg} / 100 \mathrm{~g})$, leite $(96 \mathrm{mg} / 100 \mathrm{~g})$, carne de frango $(200 \mathrm{mg} / 100 \mathrm{~g})$ e farelo de trigo (386 mg/100 g) (Mahan \& Arlin, 1994; Franco 2000).

Sartorelli (1998) e Pereira et al. (2001) encontraram teores de $\mathrm{P}$ em folhas de cenoura (material seco) de $318 \mathrm{mg} / 100 \mathrm{~g}$ e $410 \mathrm{mg} / 100 \mathrm{~g}$, respectivamente.

Stephan et al. (1996) destacaram o teor de K em folhas de cenoura como sendo de $3465 \mathrm{mg} / 100 \mathrm{~g}$, que é superior ao encontrado nas folhas de cenoura (material seco) analisadas (Tabela 5).

Kawashima (1997), analisando os teores de minerais em algumas hortaliças (alface, agrião, rúcula, couve, couve-chinesa, escarola e repolho), verificou que o nível de $\mathrm{K}$ é o mais alto entre todos os elementos e contrasta principalmente com os teores de $\mathrm{Na}$, que são muito baixos. Segundo o autor, das hortaliças estudadas, a que possui maior teor de $\mathrm{K}$ é a couve. $\mathrm{O}$ mesmo autor relata que são esperados teores elevados de $\mathrm{K}$ em hortaliças e frutas. $\mathrm{O}$ íon $\mathrm{K}^{+}$é necessário para o metabolismo de carboidratos e proteínas.

Stephan et al. (1996) verificaram valor de 1730 $\mathrm{mg} / 100 \mathrm{~g}$ de Ca para folhas de cenoura, o qual é muito próximo ao encontrado nas folhas de cenoura analisadas (Tabela 5).

Os teores de $\mathrm{Ca}$ apresentados por Franco (2000) para o leite de vaca in natura, gema de ovo cru, espinafre cru e agrião são: $114 \mathrm{mg} / 100 \mathrm{~g}, 109 \mathrm{mg} / 100 \mathrm{~g}, 95$ $\mathrm{mg} / 100 \mathrm{~g}$ e $168 \mathrm{mg} / 100 \mathrm{~g}$, respectivamente, sendo esses alimentos considerados como principais fontes desse mineral (Mahan \& Escott-Stump, 1998).

O Ca é um dos elementos inorgânicos mais importantes do organismo. Sua função principal é a de estruturar ossos e dentes, ativar algumas das reações da coagulação sanguínea como co-fator enzimático, ou liberar energia necessária para a contração muscular (Dutra de Oliveira \& Marchini, 1998).

O teor de $\mathrm{Mg}$ encontrado nas folhas de cenoura foi, conforme a Tabela 5, de $226 \mathrm{mg} / 100 \mathrm{~g}$.

$\mathrm{O} \mathrm{Mg}$ ocorre em abundância nos alimentos, e uma dieta normal é geralmente adequada para provê-lo. Leite, cereais e hortaliças fornecem cerca de 2/3 do teor diário necessário (Franco, 2000).

Analisando os teores de minerais em três hortaliças, Santos (2000) encontrou, para Mg, valores de $292,2 \mathrm{mg}$, para couve; $192,8 \mathrm{mg}$, para folhas de brócolo e 154,4 mg para folhas de couveflor. $\mathrm{O} \mathrm{Mg}$ desempenha papel fundamental no metabolismo dos carboidratos, lipídios, proteínas e ácidos nucléicos (Dutra de Oliveira \& Marchini, 1998).

O teor de Mn encontrado nas folhas de cenoura (material seco) foi de 5,50 mg/100 g, que é inferior ao teor encontrado nas folhas de cenoura estudadas por Stephan et al. (1996), de $12 \mathrm{mg} / 100 \mathrm{~g}$ b.s., e por Sartorelli (1998), de 9,48 mg/100 g b.s. Franco (2000) cita alguns alimentos com teores de Mn próximos ao encontrado para as folhas de cenoura, como agrião $(4,0 \mathrm{mg} / 100 \mathrm{~g})$, aveia $(5,0$ $\mathrm{mg} / 100 \mathrm{~g})$ e soja $(4,10 \mathrm{mg} / 100 \mathrm{~g})$.

Conforme Tabela 5, o teor médio de Zn encontrado nas folhas de cenoura foi de $5,70 \mathrm{mg} / 100 \mathrm{~g}$. Sartorelli (1998) encontrou 6,69 mg/100 g de teor de $\mathrm{Zn}$ em folhas de cenoura (material seco). 
TABELA 5 - Valores médios e respectivos erros padrão de minerais*.

\begin{tabular}{cccccccccc}
\hline & \multicolumn{8}{c}{ Minerais (mg/100 g) das folhas de cenoura } & \\
\hline & Na & $\mathbf{P}$ & $\mathbf{K}$ & $\mathbf{C a}$ & $\mathbf{M g}$ & $\mathbf{M n}$ & $\mathbf{Z n}$ & $\mathbf{F e}$ \\
\hline Folha de & 32,80 & 320 & 2744 & 1970 & 226 & 5,50 & 5,70 & 57,10 \\
Cenoura & $(0,65)$ & $(4,90)$ & $(4,90)$ & $(17,32)$ & $(2,45)$ & $(0,87)$ & $(1,15)$ & $(1,30)$ \\
\hline
\end{tabular}

* Resultados expressos na base seca.

Franco (2000) cita a aveia e a lentilha seca como boas fontes de $\mathrm{Zn}$, ambas com teores de $5,0 \mathrm{mg} / 100 \mathrm{~g}$. Comparando os teores de $\mathrm{Zn}$ encontrados no presente trabalho com os dos vegetais considerados como boas fontes, verifica-se que as folhas de cenoura estudadas podem ser consideradas como boa fonte desse mineral. $\mathrm{O} \mathrm{Zn}$ é essencial para o metabolismo da vitamina A que, por sua vez, é essencial para a síntese de hemoglobina (Lonnerdal, 1988).

$\mathrm{O}$ teor de $\mathrm{Fe}$ encontrado na folha de cenoura em $100 \mathrm{~g}$ do material seco foi de $57,10 \mathrm{mg} / 100 \mathrm{~g}$.

$\mathrm{O}$ Fe presente nas carnes vermelhas e vísceras de animais é biologicamente mais disponível por ser ligado ao heme e absorvido diretamente pelas células da mucosa intestinal. Hortaliças e feijões secos representam as melhores fontes vegetais de Fe. De forma geral, os vegetais são ricos em $\mathrm{Fe}$, embora a presença de outros compostos, como fibras alimentares, fitatos e oxalatos, tornem o Fe menos absorvível pelo intestino humano (Mahan \& Arlin, 1994; Dutra de Oliveira \& Marchini, 1998).

$\mathrm{O} \mathrm{Fe}$ exerce funções como elemento estrutural do grupo heme na hemoglobina, proteína responsável pelo transporte do oxigênio e do gás carbônico no sangue (Dutra de Oliveira \& Marchini, 1998).

\section{CONCLUSÕES}

Nas condições experimentais em que foi realizado o presente trabalho, e pelos resultados obtidos, podese concluir:

a) A folha de cenoura destaca-se como importante fonte de vitamina $\mathrm{C}, \beta$-caroteno e minerais, sobressaindo-se o $\mathrm{Ca}$ e o $\mathrm{Fe}$.

b) A folha de cenoura pode ser indicada como boa fonte de fibras insolúveis, as quais são indicadas na prevenção de doenças gastrointestinais.

c) O nitrato presente está dentro do aceitável pela Organização Mundial de Saúde e, conseqüentemente, as folhas de cenoura podem ser aproveitadas na alimentação humana, sem riscos à saúde.

\section{REFERÊNCIAS BIBLIOGRÁFICAS}

ARAÚJO, J. M. A. Química de alimentos: teoria e prática. Viçosa: UFV-Imprensa Universitária, 1995. 335 p.

ASSOCIATION OF OFFICIAL ANALYTICAL CHEMISTRY. Official methods of analysis of the Association. 12. ed. Washington, 1990. $1140 \mathrm{p}$.

BRODY, T. Nutritional biochemistry. Califórnia: Academic, 1994. 658 p.

CATALDO, D. A.; HAROON, M.; SCHRADER, L. E.; YOUNGS, V. L. Rapid calometric determination of nitrate in plant tissue by nitration of salicytic acid. Communications in Soil Plant Analysis, New York, v. 6, n. 1, p. $71,1975$.

DUTRA DE OLIVEIRA, J. E.; MARCHINI, J. S. Ciências nutricionais. São Paulo: Sarvier, 1998. 403 p.

ESPÍNDOLA, F. S. Fracionamento dos vegetais verdes e obtenção de concentrados protéicos de folhas (CPF) para suplementação de alimentos e ração animal, com aproveitamento dos subprodutos. 1987. 140 f. Monografia (Graduação em Agronomia) - Universidade Federal de Uberlândia, Uberlândia.

FISKE, C. H.; SUBBAROW, W. The calorimetric determination of phophprus. Journal of Biological Chemistry, Bethesda, v. 66, p. 375-400, 1925.

FlORES, H.; CAMPOS, F. A. C. S.; SILVA, M. B. M.; LINS, M. H. C. B. Enriquecimento de alimentos: presente e futuro. Boletim da Sociedade Brasileira de Ciências e Tecnologia de Alimentos, Campinas, v. 30, n. 1, p. 49-55, jan./jun. 1998.

FRANCO, G. Tabela de composição química dos alimentos. 9. ed. São Paulo: Atheneu, 2000. 307 p. 
HULME, A. C. The biochemistry of fruits and their products. New York: Academic, 1970. v. 1, 620 p.

INSTITUTO ADOLFO LUTZ. Normas analíticas do Instituto Adolfo Lutz: métodos químicos e físicos para análise de alimentos. 3. ed. São Paulo, 1985. v. 1, 332 p.

KAMER, J. H. Van de; GINKEL, L. Van. Rapid determination of crude fiber in cereais. Cereal Chemistry, Saint Paul, v. 29, n. 4, p. 239-251, July/Aug. 1952.

KAWASHIMA, L. M. Teores totais e frações solúveis de alguns elementos minerais nutricionalmente importantes em hortaliças folhosas e efeito do cozimento sobre solubilidade e perdas. 1997. 107 f. Dissertação (Mestrado em Engenharia de Alimentos) - Universidade Estadual de Campinas, Campinas.

LONNERDAL, B. Vitamin-mineral interactions. In: BODWELL, C. E.; ERDMAN JUNIOR, J. W. Nutrientes interactions. New York: Marcel Dekker, 1988. cap. 6, p. 163-186.

MAFFIA, U. C. C. Avaliação do farelo de arroz em substituição à farinha de trigo na panificação. 1991. 122 f. Dissertação (Mestrado em Ciência e Tecnologia de Alimentos) - Universidade Federal de Viçosa, Viçosa.

MAHAN, L. K.; ARLIN, M. T. Krause: alimentos, nutrição e dietoterapia. 8. ed. São Paulo: Roca, 1994. 957 p.

MAHAN, L. K.; ESCOTT-STUMP, S. Krause: alimentos, nutrição e dietoterapia. 9. ed. São Paulo: Roca, 1998. $1179 \mathrm{p}$.

ORNELLAS, L. H. Técnica dietética: seleção e preparo de alimentos. 3. ed. Rio de Janeiro: Interamericana, 1979. $319 \mathrm{p}$.

PEREIRA, G. I. S.; PEREIRA, R. G. F. A.; BARCELOS, M. F. P.; TORGA, P. P.; TEIXEIRA, D. G. A. Caracterização química da folha de cenoura (Daucus carota L.) para utilização na alimentação hu- mana. In: CONGRESSO DA PÓS-GRADUAÇÃO DA UFLA, 10., 2001, Lavras. Anais... Lavras: UFLA, 2001. 1 CD-ROM.

POURCHET-CAMPOS, M. A. Fibra: a fração alimentar que desafia os estudiosos. Alimentos e Nutrição, São Paulo, v. 2, p. 53-63, 1990.

SANTOS, M. A. T. dos. Caracterização química das folhas de brócoli e couve-flor (Brassica oleracea $\mathbf{L}$.) para utilização na alimentação humana. 2000. 96 p. Dissertação (Mestrado em Ciência dos Alimentos) Universidade Federal de Lavras, Lavras.

SARRUGE, J. R.; HAAG, H. P. Análise química em plantas. Piracicaba: USP/ESALQ, 1974. 55 p.

SARTORELLI, C. S. C. Caracterização química da parte aérea de cenoura (Daucus carota) e beterraba (Beta vulgaris), visando ao aproveitamento na alimentação humana. 1998. 98 p. Dissertação (Mestrado em Ciência dos Alimentos) - Universidade Federal de Lavras, Lavras.

SILVA, D. J. da. Análises de alimentos: métodos químicos e biológicos. Viçosa: UFV, 1981. 166 p.

STEPHAN, M. P.; DIAS, M. M. C.; ALBERTO, G.; BENASSI, V. T.; ALMEIDA, D. L. de. Aproveitamento das ramas de cenoura para fortificação de biscoitos: análise da produção, composição mineral e protéica. In: CONGRESSO BRASILEIRO DE CIÊNCIA E TECNOLOGIA DE ALIMENTOS, 1996, Poços de Caldas. Resumos... Rio de Janeiro: CTAA-EMBRAPA, 1996. p. 49-50.

STROHECKER, R.; HENNING, H. M. Analisis de vitaminas: métodos comprobados. Madri: Paz Montalvo, 1967. $428 \mathrm{p}$.

TOYOHARA, O. Q. Determinação de nitrato, nitrito e N-nitrosaminas em lingüiças. 1989. 85 f. Dissertação (Mestrado em Tecnologia de Alimentos) - Universidade Estadual de Campinas, Campinas. 